\title{
Lung cancer care trajectory at a Canadian centre: an evaluation of how wait times affect clinical outcomes
}

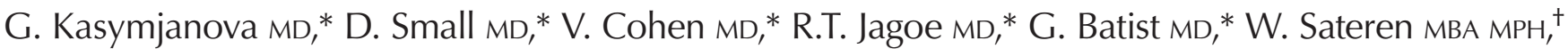 \\ P. Ernst MD, ${ }^{*}$ C. Pepe MD, ${ }^{*}$ L. Sakr MD, ${ }^{*}$ and J. Agulnik MD*
}

\begin{abstract}
Background Lung cancer continues to be one of the most common cancers in Canada, with approximately 28,400 new cases diagnosed each year. Although timely care can contribute substantially to quality of life for patients, it remains unclear whether it also improves patient outcomes. In this work, we used a set of quality indicators that aim to describe the quality of care in lung cancer patients. We assessed adherence with existing guidelines for timeliness of lung cancer care and concordance with existing standards of treatment, and we examined the association between timeliness of care and lung cancer survival.
\end{abstract}

Methods Patients with lung cancer diagnosed between 2010 and 2015 were identified from the Pulmonary Division Lung Cancer Registry at our centre.

Results We demonstrated that the interdisciplinary pulmonary oncology service successfully treated most of its patients within the recommended wait times. However, there is still work to be done to decrease variation in wait time. Our results demonstrate a significant association between wait time and survival, supporting the need for clinicians to optimize the patient care trajectory.

Interpretation It would be helpful for Canadian clinicians treating patients with lung cancer to have wait time guidelines for all treatment modalities, together with standard definitions for all time intervals. Any reductions in wait times should be balanced against the need for thorough investigation before initiating treatment. We believe that our unique model of care leads to an acceleration of diagnostic steps. Avoiding any delay associated with referral to a medical oncologist for treatment could be an acceptable strategy with respect to reducing wait time.

Key Words Lung cancer, wait times

Curr Oncol. 2017 Oct;24(5):302-309

www.current-oncology.com

\section{INTRODUCTION}

Lung cancer is one of most common cancers in Canada, with 28,400 new cases diagnosed each year ${ }^{1}$. Even with treatment, the 5 -year survival rate for lung cancer is $17 \%^{1}$. In contrast, the 5 -year survival rates for breast and prostate cancer are $87 \%$ and $95 \%$ respectively ${ }^{2}$.

The Institute of Medicine in the United States recognizes timeliness as one of six important quality-of-care dimensions $^{3}$. Various guidelines to establish standards for timely care for patients with known or suspected lung cancer have been published, but prompt access to and delivery of lung cancer care can be difficult to achieve in a public health care system. Between 1998 and 2009, the British Thoracic Society ${ }^{4}$, the United Kingdom's National Health Service Cancer Plan $^{5-7}$, the RAND Corporation ${ }^{8,9}$, the American College of Chest Physicians ${ }^{10}$, and Cancer Care Ontario ${ }^{2}$ all published recommendations for target time intervals in the trajectory of diagnosis and treatment for lung cancer (Table I). However, although timely care can contribute substantially to quality of life and emotional well-being for patients, the literature concerning the effect of timeliness on other patient outcomes does not show a clear association between earlier initiation of anticancer treatment and improved survival ${ }^{11-14}$. 
TABLE I Timeliness of care for patients with lung cancer

\begin{tabular}{|c|c|c|c|c|c|}
\hline \multirow[t]{2}{*}{ Interval } & \multicolumn{5}{|c|}{ Recommended wait time (days) ${ }^{a}$} \\
\hline & $\begin{array}{l}\text { British Thoracic } \\
\text { Society }^{4}\end{array}$ & $\begin{array}{l}\text { U.K. National } \\
\text { Health } \\
\text { Service }^{5-7}\end{array}$ & $\begin{array}{c}\text { RAND } \\
\text { Corporation }^{8,9}\end{array}$ & $\begin{array}{c}\text { American } \\
\text { College of Chest } \\
\text { Physicians }^{10}\end{array}$ & $\begin{array}{c}\text { Cancer Care } \\
\text { Ontario }^{2}\end{array}$ \\
\hline Referral $\rightarrow$ lung cancer specialist & 7 & 14 & & & \\
\hline Lung cancer specialist $\rightarrow$ diagnosis & 30 & & & & 35 \\
\hline Referral $\rightarrow$ first treatment & 62 & 62 & & & 60 \\
\hline Lung specialist $\rightarrow$ surgery & 56 & & & 104 & 68 \\
\hline Diagnosis $\rightarrow$ surgery consult & 60 & & & & \\
\hline Surgery consult $\rightarrow$ surgery & 28 & & & & $14-84$ \\
\hline Surgery $\rightarrow$ adjuvant chemotherapy & 120 & & & 120 & \\
\hline Diagnosis $\rightarrow$ first treatment & 30 & 31 & 42 & 35 & 52 \\
\hline Diagnosis $\rightarrow$ chemotherapy & 28 & 30 & 42 & 39 & \\
\hline Diagnosis $\rightarrow$ radiotherapy & & & 42 & & \\
\hline Decision-to-treat $\rightarrow$ treatment other than surgery & $7-28$ & & & & \\
\hline Ready to treat $\rightarrow$ radiation & & & & & 28 \\
\hline
\end{tabular}

a Reported as median delay to specialist consultation and treatment.

Here, we describe the timeliness of care in lung cancer patients treated by an interdisciplinary team at the Segal Cancer Centre of the Sir Mortimer B. Davis Jewish General Hospital in Montreal. This team is composed of dual-specialized pulmonologist-oncologists, nurses, palliative care specialists, surgeons, radiation oncologists, nutritionists, and specialists in complementary medicine. After a comprehensive review of the relevant literature, a set of quality indicators was selected. We assessed adherence to existing guidelines for timeliness of lung cancer care and concordance with existing standards of treatment. The association between timeliness of care and lung cancer survival was also examined.

\section{METHODS}

\section{Selection of Quality Indicators}

The lung cancer-specific quality indicators (Table II) were selected based on a review of the literature and evidence-based practice guidelines available in 2015 . Most of the indicators were selected from the British Thoracic Society guideline, with the exception of diagnosis to radiotherapy (RT), which was selected from the RAND Corporation guideline.

\section{Lung Cancer Registry}

Patients with lung cancer diagnosed between 1 January 2010 and 31 December 2014 were identified using the Jewish General Hospital's Pulmonary Division Lung Cancer Registry. Use of the registry database-which contains information on referral patterns, diagnostic and staging evaluations, clinical extent of disease, pathology, and treatments-has been approved by the Research Ethics Committee since 2006.

Most patients were diagnosed and staged under the supervision of a pulmonary specialist who was also
TABLE II Selected quality indicators

\begin{tabular}{lc}
\hline \multicolumn{1}{c}{ Interval } & $\begin{array}{c}\text { Target wait time } \\
\text { (days) }\end{array}$ \\
\hline GP referral $\rightarrow$ lung cancer specialist & 7 \\
Referral $\rightarrow$ diagnosis & 30 \\
Diagnosis $\rightarrow$ treatment & 30 \\
GP referral $\rightarrow$ treatment & 62 \\
Diagnosis $\rightarrow$ surgery consult & 60 \\
Surgery consult $\rightarrow$ surgery & 28 \\
Surgery $\rightarrow$ adjuvant chemotherapy & 120 \\
Diagnosis $\rightarrow$ chemotherapy & 28 \\
Diagnosis $\rightarrow$ radiotherapy & 42 \\
\hline
\end{tabular}

$\mathrm{CP}=$ general practitioner.

responsible for coordination and continuity of oncology care. Patients were staged using imaging, according to the 7th edition of the International Association for the Study of Lung Cancer staging classification manual ${ }^{15}$. All patients were presented at an interdisciplinary tumour board conference at least once before their first treatment. The stage was confirmed by consensus of the tumour board member physicians.

For the purpose of the present analysis, we extracted date of referral to a lung cancer specialist (medical oncologist or pulmonary specialist), date of first contact with the lung cancer specialist, date of diagnosis, date of first treatment, pathology or histologic diagnosis, stage, and patient demographics, including age, sex, postal code of primary residence, Eastern Cooperative Oncology Group performance status, weight loss, and smoking status. Components of lung cancer treatment reported in the patterns of care included surgery, RT, combination therapy, and chemotherapy. 
Patients referred for a second opinion or being treated elsewhere were excluded because they could potentially present with negative time intervals.

\section{Definitions of Terms Used in the Study}

"Date of diagnosis" was defined as the date of the diagnostic biopsy procedure that provided the pathology diagnosis.

"Diagnosis-to-treatment interval" was defined as the time between the diagnosis and initiation of treatment.

"Treatment" was defined as any specific anticancer treatment (surgery, RT, or chemotherapy) within 6 months of diagnosis and was categorized as surgery, adjuvant chemotherapy or RT, combined chemoradiotherapy, primary systemic chemotherapy, targeted therapy, and best supportive care

Lung cancer was categorized as "early" (stages I and II), "locoregionally advanced" (stage III), or "advanced" (stage IV).

"Survival" was defined as the interval between the date of the first treatment and the date of death or last follow-up.

\section{Statistical Analysis}

Means, medians, and interquartile ranges were used to summarize patient characteristics and time intervals. For each of the intervals of interest, patients were assigned a binary variable to indicate whether they were seen within the recommended waiting period for their treatment modality. The characteristics of patients falling within and outside the recommended waiting periods were first examined in univariate analysis using Pearson chi-square tests. Variables of interest were age, histologic diagnosis, stage, Eastern Cooperative Oncology Group performance status, source of consultation request, and first treatment modality. Multiple logistic regression analysis was used to identify predictors of recommended wait times being met. The variables described in univariate analysis were also entered into the logistic regression analyses. A $p$ value less than 0.05 was considered significant. Odd ratios (oRs) and $95 \%$ confidence intervals (CIs) were calculated for each variable in the model. Survival was analyzed using the Kaplan-Meier method and Cox regression statistics. All analyses were performed using the JMP software application (version 11.2: SAS Institute, Cary, NC, U.S.A.).

\section{RESULTS}

\section{Patient Characteristics}

During the study period, 751 patients were diagnosed with primary non-small-cell lung cancer (NSCLC, 90\%) or smallcell lung cancer (SCLC) at the interdisciplinary pulmonary oncology referral centre. Of those patients, $69 \%$ were referred from within the hospital's immediate region (Island of Montreal). The others originated from other regions of the province of Quebec.

For a variety of reasons, 89 patients (11.9\%) received best supportive care and no cancer-specific treatment. Of those patients, $64 \%$ were 70 years of age or older, $72 \%$ had a performance status of 2 or greater, and $80 \%$ had advancedstage lung cancer. The 662 patients who did receive anticancer treatment underwent any one or a combination of surgery, RT, and systemic therapy (Figure 1). Potentially curative treatment (surgery with or without adjuvant chemotherapy or radiation, or with both; definitive radiation; or combined chemoradiation) was delivered to 310 patients $(41.3 \%)$. The remaining 352 patients $(46.9 \%)$ had advanced disease not considered curable and were thus treated with either chemotherapy or palliative radiation (Figure 2). Table in presents the characteristics of the 751 patients. Most patients had advanced-stage NSCLC.

\section{Wait Times and Factors Predicting Delay}

Of the 751 patients, $520(69 \%)$ were referred by general practitioners, and 231 (31\%) were referred to the pulmonary specialist from the emergency department or from an inpatient medical ward. Most in-hospital patients were seen by a pulmonary specialist on the day of referral. When in-hospital and emergency department referrals were excluded, about $60 \%$ of patients met the target of first contact with the team within 7 days (median wait time: 6 days). In the logistic regression models, no patient factors were associated with the interval length, including sex, age, geographic area of residence, smoking history, weight loss, disease stage, or Eastern Cooperative Oncology Group performance status.

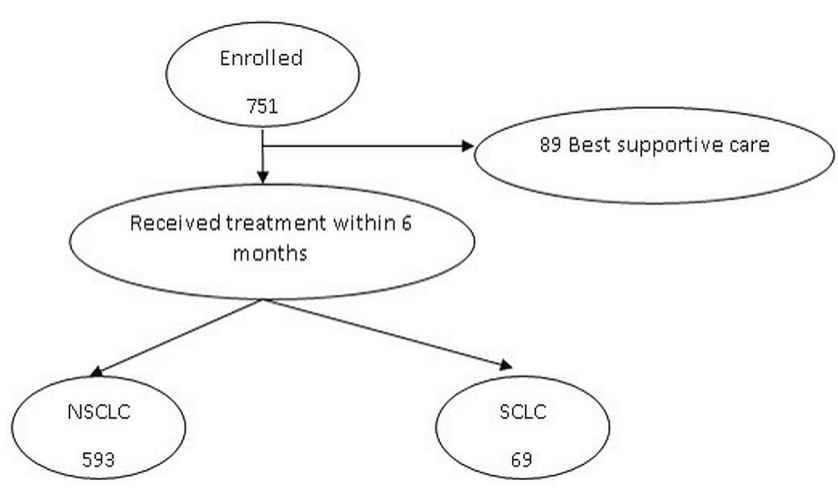

FIGURE 1 Flow chart of the study cohort selection. NSCLC = nonsmall-cell lung cancer; SCLC = small-cell lung cancer.

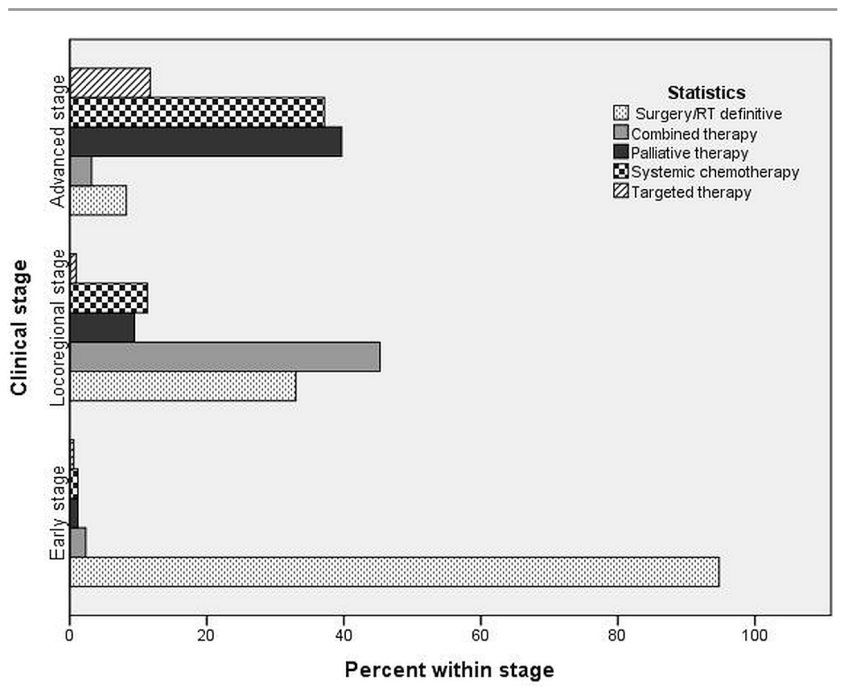

FIGURE 2 Treatment types for non-small-cell lung cancer. RT = radiation therapy. 
TABLE III Patient characteristics

\begin{tabular}{|c|c|}
\hline Variable & Value \\
\hline Patients $(n)$ & 751 \\
\hline \multicolumn{2}{|l|}{$\operatorname{Sex}[n(\%)]$} \\
\hline Men & $383(49.0)$ \\
\hline Women & $368(51.0)$ \\
\hline \multicolumn{2}{|l|}{ Age (years) } \\
\hline Mean & 67 \\
\hline Range & $29-93$ \\
\hline \multicolumn{2}{|l|}{ Smoking status $[n(\%)]$} \\
\hline Smoker & $312(41.5)$ \\
\hline Ex-smoker & $325(43.3)$ \\
\hline Never-smoker & $113(15.0)$ \\
\hline Missing & $1(0.2)$ \\
\hline \multicolumn{2}{|l|}{ Diagnosis $[n(\%)]$} \\
\hline NSCLC & $678(90.3)$ \\
\hline Adenocarcinoma & $520(77.0)$ \\
\hline Squamous carcinoma & $91(14.0)$ \\
\hline Undifferentiated & $29(4.0)$ \\
\hline Adenosquamous carcinoma & $9(1.0)$ \\
\hline Large cell & $16(2.0)$ \\
\hline Other & $13(2.0)$ \\
\hline SCLC & $73(9.7)$ \\
\hline \multicolumn{2}{|l|}{ NSCLC stage $[n(\%)]$} \\
\hline Early-stage (IA-IIB) & $177(26.0)$ \\
\hline Locally advanced (IIIA-IIIB) & $111(16.5)$ \\
\hline Advanced (IV) & $390(57.4)$ \\
\hline \multicolumn{2}{|l|}{ SCLC stage $[n(\%)]$} \\
\hline Limited & $27(37.0)$ \\
\hline Extensive & $46(63.0)$ \\
\hline \multicolumn{2}{|c|}{ First consultation with pulmonary physician [ $n(\%)]$} \\
\hline Outpatient referral from GP or specialist & $520(69.0)$ \\
\hline Inpatient consult & $66(9.0)$ \\
\hline Referral from emergency department & $165(22.0)$ \\
\hline
\end{tabular}

$\mathrm{NSCLC}=$ non-small-cell lung cancer; $\mathrm{SCLC}=$ small-cell lung cancer; $\mathrm{GP}=$ general practitioner.

Table IV outlines the median wait times and interquartile ranges for the clinical intervals examined in the study and the proportion of patients seen within the target wait times.

The median time from first visit with a lung cancer specialist to diagnosis was 21 days, and $57 \%$ of patients were diagnosed within the target wait time of 30 days. More advanced clinical stage was the only factor that was significantly associated with a reduced interval (oR: $0.418 ; p=0.003$ ). The median wait time for advanced-stage disease was 13 days; it was 46 days for early and locallyadvanced disease.

The median wait time from the date of referral to initiation of cancer treatment was 53 days for disease of all stages, 71 days for early-stage disease, and 39 days for advanced-stage disease. Of the patients overall, $54 \%$ received their first treatment within 62 days from referral. The median wait time from diagnosis to first treatment was 27 days, and $56 \%$ of patients received their first treatment within the targeted 30 days from diagnosis. Patients with locally-advanced and advanced NscLC were more likely to be treated within the target time (oR: $0.420 ; p<0.04$ ). Compared with patients having limited scLC, those with extensive scLC also waited a significantly shorter time from diagnosis to first treatment: 14 compared with 20 days (oR: $0.26 ; p=0.013$ ).

Of patients with early-stage NsCLC, 95\% underwent either surgery or stereotactic body radiation therapy. Of the patients with locally advanced disease, $24 \%$ underwent surgery, and $43 \%$ were treated with combined chemoradiation. For the patients with advanced cancer, the initial treatment was palliative radiation for symptom relief or distant metastases in 36\%; chemotherapy was the initial treatment in $30 \%$. Mutations in the epidermal growth factor receptor gene $(E G F R)$ or the anaplastic lymphoma kinase $(A L K)$ fusion oncogene were found in 68 patients $(10 \%)$. Of those patients, 29 (43\%) underwent surgery for early-stage disease with no evidence of progression; the other 39 (57\%) were treated with targeted therapy (Figure 2).

The median wait time from diagnosis to initiation of chemotherapy was 32 days, and $47 \%$ of patients started treatment within 28 days. Patients with extensive scLc had a lesser chance of a prolonged wait time (oR: $0.211 ; p=0.001$ ).

Radiation treatment was given within the target wait time of 35 days from the date of diagnosis for $56 \%$ of all patients. Median wait time for patients receiving curative RT was 43 days; it was 29 days for palliative RT $(p<0.001)$.

Among surgical patients $(n=171), 135$ had early-stage disease, and 36 had locally-advanced disease. All 36 of the latter patients had pathologically proven N1 disease (by biopsy) before surgery. We chose to report two key intervals: days from the date of surgical consultation to the surgery date, with a target wait time of 28 days, and days from surgery to the initiation of adjuvant therapy, with a target wait time of 120 days. Within the target times, $62 \%$ of patients received their surgery, and $100 \%$ received their adjuvant chemotherapy.

\section{Survival}

The survival analysis was performed only for the cohort of 593 NSCLC patients who received anticancer treatment; patients with SCLC and those who received only best supportive care were excluded. During the observation period, 360 deaths occurred. The 1-year overall survival rate was $56 \%$, and the 5 -year overall survival rate was $23 \%$. Table v shows detailed survival rates by disease stage, together with recently published data from other countries.

In an unadjusted analysis, we observed a statistically significant association between diagnosis-to-treatment interval and overall survival; delay in treatment increased the risk of death (Figure 3). Patients who began treatment within 30 days from diagnosis experienced a median survival duration of 14.8 months (95\% CI: 9.4 to 20.3 months); for those who exceeded the target, median survival duration was 11.0 months (95\% CI: 8.8 to 13.1 months; $p=0.037$ ). Stage at diagnosis was a significant confounder, with statistically significant positive and negative effects on survival. 
TABLE IV Wait times

\begin{tabular}{|c|c|c|c|c|c|c|c|}
\hline \multicolumn{2}{|r|}{ Interval } & \multirow{2}{*}{$\begin{array}{l}\text { Target time } \\
\text { (days) }\end{array}$} & \multicolumn{2}{|c|}{ Patients $(n)$} & \multicolumn{3}{|c|}{ Wait times at Jewish General Hospital } \\
\hline & & & All & Data missing & Median (days) & IQR (days) & Met target $(\%)$ \\
\hline 1 & GP referral to pulmonary specialist ${ }^{\mathrm{a}}$ & 7 & 520 & 29 & 6 & $1-13$ & 60 \\
\hline 2 & Pulmonary specialist $\rightarrow$ diagnosis ${ }^{\mathrm{a}}$ & 30 & 520 & 0 & 21 & $1-68$ & 57 \\
\hline 3 & Referral $\rightarrow$ first treatment ${ }^{b}$ & 62 & 662 & 26 & 53 & $21-94$ & 54 \\
\hline 4 & Diagnosis $\rightarrow$ treatment ${ }^{b}$ & 30 & 662 & 0 & 27 & $5-45$ & 56 \\
\hline 5 & Pulmonary specialist $\rightarrow$ treatment $^{b}$ & 60 & 662 & 0 & 54 & $26-92$ & 58 \\
\hline 6 & Diagnosis $\rightarrow$ chemotherapy & 28 & 293 & 0 & 32 & $20-46$ & 47 \\
\hline & Combined treatment & & 86 & 0 & 36 & $22-53$ & \\
\hline & Double-agent & & 145 & 0 & 29 & $19-43$ & \\
\hline & Single-agent & & 23 & 0 & 35 & $21-53$ & \\
\hline & Targeted therapy & & 39 & 0 & 36 & $20-58$ & \\
\hline 7 & Diagnosis $\rightarrow$ radiation therapy & 42 & 191 & 0 & 35 & $19-55$ & 56 \\
\hline 8 & Surgery consult $\rightarrow$ surgery & 28 & 169 & 17 & 26 & $14-42$ & 62 \\
\hline 9 & Surgery $\rightarrow$ adjuvant chemotherapy & 120 & 40 & 2 & 58 & $53-66$ & 100 \\
\hline
\end{tabular}

TABLE V One-year survival ${ }^{16}$

\begin{tabular}{lccccc}
\hline \multirow{2}{*}{ Stage } & \multicolumn{5}{c}{ Survival (\%) } \\
\cline { 2 - 6 } & Canada & Denmark & Sweden & United Kingdom & Jewish General Hospital \\
\cline { 2 - 6 } I & 86.2 & 75.0 & 88.8 & 71.1 & 90 \\
II & 79.0 & 60.8 & 70.3 & 58.6 & 72 \\
III & 43.2 & 45.0 & 47.1 & 34.4 & 30 \\
IV & 16.8 & 21.4 & 25.9 & 15.5 & 30 \\
All & 41.8 & 35.4 & 46.1 & 28.8 & 56 \\
\hline
\end{tabular}

In advanced-stage disease, compared with locoregional disease, an inverse association was found between survival and the diagnosis-to-treatment interval (Table vi).

The Cox regression analysis was stratified by stage (Table viI). The diagnosis-to-treatment interval was an independent prognostic factor for both early-stage and advanced-stage cancer. In the early and locoregional stages, a shorter wait time had a protective effect (meeting the target time was associated with a lower hazard ratio), and in advanced-stage cancer, the effect was opposite (meeting the target time was associated with a higher hazard ratio). Among patients with locoregional disease, meeting the target time was associated with a $90 \%$ increase in median survival duration (17.2 months vs. 32.7 months).

\section{DISCUSSION}

Our study demonstrates that most of our patients were successfully diagnosed and treated within the recommended wait times. The chosen target wait times are realistic, and adherence has a positive effect on outcome. However, much work remains to decrease variation in wait time. Of our referred patients, $60 \%$ were seen by a pulmonologist

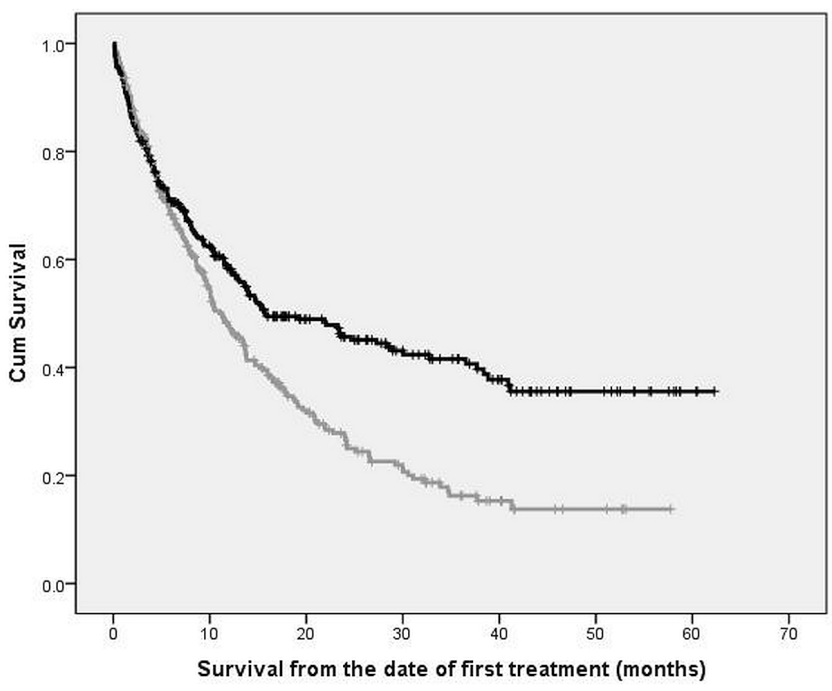

FIGURE 3 Association of survival with timeliness of care (unadjusted analysis). The black curve tracks patients treated within 30 days from diagnosis. The grey curve tracks patients treated more than 30 days from diagnosis. 
TABLE VI Association between the 30-day diagnosis-to-treatment target being met and median survival (in months), by stage

\begin{tabular}{lccc}
\hline \multicolumn{1}{c}{ Stage } & Diagnosis-to-treatment interval & Median survival (months) & $\mathbf{9 5 \%} \mathbf{C l}$ \\
\hline Early & $\leq 30$ Days & NR & 0.09 \\
& $>30$ Days & 34.6 & 0.04 \\
Locoregional & $\leq 30$ Days & 32.7 & 13.4 to 52.1 \\
& $>30$ Days & 17.2 & 10.4 to 24.0 \\
Advanced & $\leq 30$ Days & 5.6 & 3.9 to 7.3 \\
& $>30$ Days & 7.3 & 5.6 to 9.1 \\
\hline
\end{tabular}

$\mathrm{Cl}=$ confidence interval; $\mathrm{NR}=$ not reached.

TABLE VII Proportional hazards model of survival for early- compared with advanced-stage non-small-cell lung cancer

\begin{tabular}{|c|c|c|c|c|c|c|c|}
\hline \multirow[t]{3}{*}{ Variable } & \multirow[t]{3}{*}{ Comparison } & \multicolumn{6}{|c|}{ Stage } \\
\hline & & \multicolumn{3}{|c|}{ Early } & \multicolumn{3}{|c|}{ Advanced } \\
\hline & & HR & $95 \% \mathrm{Cl}$ & $p$ Value & HR & $95 \% \mathrm{CI}$ & $p$ Value \\
\hline Age & $\leq 65$ Years vs. $>65$ years & 0.86 & 0.59 to 1.23 & 0.398 & 0.76 & 0.61 to 1.01 & 0.060 \\
\hline Sex & Women vs. men & 0.67 & 0.47 to 0.96 & 0.031 & 0.79 & 0.62 to 0.99 & 0.046 \\
\hline ECOG PS & $\leq 1$ vs. $>1$ & 0.63 & 0.37 to 1.07 & 0.090 & 0.36 & 0.28 to 0.46 & $<0.001$ \\
\hline 30-Day target & Met vs. not met & 2.07 & 1.45 to 2.97 & $<0.001$ & 0.72 & 0.58 to 0.92 & 0.008 \\
\hline
\end{tabular}

$\mathrm{HR}=$ hazard ratio; $\mathrm{Cl}$ = confidence interval; ECOG PS = Eastern Cooperative Oncology Group performance status.

within 7 days; the Cancer Quality Council of Ontario (CQCO) reported that $55 \%$ were seen within 14 days ${ }^{17}$. That difference might be explained by an acceleration of diagnostic steps, avoiding the delay associated with referral from the pulmonologist to the medical oncologist for treatment. Having patients diagnosed, staged, and treated under the supervision of the same pulmonary specialist shortens the treatment wait time at almost no cost. Mathews and colleagues ${ }^{18}$ reported that wait times relate to the performance of groups of individuals rather than to the performance of a single health care provider and can be shortened simply by improving the organization of health services in a way that does not require any additional costs-such as continuity of care. The median wait time to diagnosis for our patients was shorter than the target of 30 days, with $57 \%$ being diagnosed within 30 days. Our $88 \%$ rate of active treatment is comparable to the $70 \%-87 \%$ rate reported by other interdisciplinary teams ${ }^{19-22}$.

Not surprisingly, our median wait times to first treatment were shorter than the chosen targets. Nadpara et $a l .{ }^{23}$ reported a median of 22 days from diagnosis to treatment in a registry-linked database study. Those authors found that patients receiving RT had the shortest wait time; patients who received surgery had the longest wait time. Yorio et al. ${ }^{24}$ reported a median of 33 days and concluded that the length of the interval was associated with the type of the hospital (private vs. public). Li and coauthors $^{25}$ reported a 41-day interval from diagnosis to all modalities of first treatment in a retrospective study from Alberta. In our cohort, a significant number of patients with advanced disease started treatment earlier, and they more frequently met the target interval. The shorter delay for patients with more advanced stage is consistent with the results reported by Forrest et al. ${ }^{26}$, who used the term "sicker quicker" to apply to older patients with a poor performance status and advancedstage disease who are seen by pulmonary specialists and diagnosed within a shorter period. Those authors concluded that socioeconomic inequalities appear to substantially account for differences in lung cancer survival. Our findings accord with findings from the U.S. National Cancer Institute comprehensive cancer centres and the U.S. Department of Veterans Affairs. Bilimoria et $a l .{ }^{27}$ observed that a delay of more than 30 days was more likely for patients with early-stage disease and for elderly patients with multiple comorbidities.

As already mentioned, patients with earlier-stage disease often receive treatments that require more complex planning, or are more difficult to stage, or require a surgical consultation before resection, all of which add to the wait time. Median wait times for cancer surgery for all cancer types in Ontario increased to 33 days in 2000 from 14 days in 1984-1987-an increase that is likely also reflected in Quebec wait times ${ }^{28}$. In our cohort, the median wait time from initial contact with the thoracic surgeon to the actual surgery was 21 days. That interval is shorter than the 82 days reported by Liberman et al. ${ }^{29}$ and the 32 days measured by Lee et $a l .{ }^{30}$ from the date that a patient was added to a surgical waiting list. The CQCo stated that, in $2010,75 \%$ of patients underwent surgery within the targeted number of days for various priority operations. Although we recognize that comparing a single-institution study to population-based analysis is not fair, there is clearly room for improvement: only $62 \%$ of patients underwent surgery within 28 days of being seen by the surgeon and of being placed on the wait list for surgery. 
In this study of adherence to treatment guidelines, our patients tended, overall, to receive care concordant with treatment guidelines and comparable to the care reported by the CQCO and the U.S. Surveillance, Epidemiology, and End Results program ${ }^{17,31}$. Of our early-stage NSCLC patients, $95 \%$ (compared with the $71 \%-85 \%$ reported by the CQCO and Surveillance, Epidemiology, and End Results program) underwent surgery. In patients with locally-advanced disease, guideline-recommended combined chemotherapy and RT were administered to $43 \%$ of patients, compared with the $30 \%$ reported by the CQCO. Our retrospective evaluation considered patients at a single institution, with the limitations that such an analysis implies.

Wait times for RT also depended on the intent of the treatment. Compared with palliative RT, curative RT requires more complex planning, potentially leading to longer delays ${ }^{32,33}$. The CQCO reported RT within the target time for a higher proportion of patients than we found, $75 \%$ compared with $56 \%$.

Survival is a key index of the effectiveness of a cancer care program. Although our data do not necessary reflect population data, our overall 1- and 5-year survival rates were similar to those in other developed countries such as Australia, England, and Sweden ${ }^{34}$. In that International Cancer Benchmarking Partnership project, survival was reported as net survival, in which background mortality in the general population has been taken into account. That methodology might explain the slight survival benefit seen in our patients. The available published evidence for an effect of timeliness of care on survival remains indirect and conflicting ${ }^{24,35}$. A systematic review from Olsson et al. ${ }^{9}$ found no clear evidence that a timely diagnostic pathway resulted in improved survival. Forrest ${ }^{12}$ and Yilmaz ${ }^{36}$, with their colleagues, also reported that timeliness of referral and treatment had no effect on survival. In contrast, two other studies described a negative effect of not meeting timely care guidelines ${ }^{14,37}$. Chen et al. ${ }^{35}$ performed a meta-analysis investigating the effect of wait time on local control rates for several cancers treated with RT. The rate ratio for local recurrence was 1.14 per 4 weeks of delay $(95 \%$ CI: 1.09 to 1.21 ).

We found that meeting a diagnosis-to-treatment interval target of 30 days was an independent prognostic factor for survival when stratified for the strong confounding effect of stage. In early and locally-advanced disease, meeting the target had a protective effect and was associated with improved survival. We observed a tendency toward better survival in patients with stage III cancer meeting the target. However, in advanced NSCLC, the effect of diagnosis-to-treatment interval was inverted, with a longer interval being associated with better survival. Patients with advanced-stage disease typically do not require as much work-up as early-stage patients and often also require only a pulmonary specialist to diagnose and treat the disease. They are often symptomatic at presentation and are treated faster because of an urgency to relieve those symptoms. For that reason, it is not surprising that the association between survival and wait time in advanced-stage disease is reversed. Gonzalez-Barcala et $a l .{ }^{38}$ reported that patients with advanced-stage disease have a shorter treatment delay and that a longer treatment delay was associated with longer survival. However, we cannot exclude the possibility that cancer biology might play a role in that association.

A few limitations to this study are noteworthy. It was carried out using data from a single institution and is relatively small compared with population-based studies. A number of patients with negative intervals were excluded from the analyses because their trajectory did not match the standard clinical picture. Those patients had been referred for a second opinion after starting treatment elsewhere. Finally, some patients required additional investigations, and the limited availability of certain diagnostic equipment, such as the nuclear scanner, added to wait times.

\section{CONCLUSIONS}

This real-world experience of a Canadian interdisciplinary pulmonary oncology centre reveals several strengths and weaknesses. Most patients undergoing RT and surgery were seen within recommended wait times. Our results demonstrate a significant association of wait time and survival, especially in locoregional NSCLC, supporting a need for clinicians and hospital administrators to optimize the patient care trajectory. It would be helpful for Canadian clinicians treating patients with known or suspected lung cancer to have wait time guidelines for all treatment modalities, together with standard definitions for all time intervals. Efforts in reducing wait times should be balanced against the need for thorough investigation and staging of each patient before treatment begins. We believe that our unique model of care leads to an acceleration of diagnostic steps; avoiding any delay associated with referral to a medical oncologist for treatment could be an acceptable strategy with respect to reducing wait time.

\section{CONFLICT OF INTEREST DISCLOSURES}

We have read and understood Current Oncology's policy on disclosing conflicts of interest, and we declare that we have none.

\section{AUTHOR AFFILIATIONS}

*Peter Brojde Lung Cancer Centre, Segal Cancer Centre, Sir Mortimer B. Davis Jewish General Hospital, Rossy Cancer Network, and McGill University, Montreal, QC; 'Rossy Cancer Network, McGill University, Montreal, QC.

\section{REFERENCES}

1. Canadian Cancer Society's Advisory Committee on Cancer Statistics. Canadian Cancer Statistics 2014. Toronto, ON: Canadian Cancer Society; 2014.

2. Canadian Cancer Society. Lung Cancer Statistics [Web page, Ontario version]. Toronto, ON: Canadian Cancer Society; 2015. [Current version available at: http://www. cancer.ca/en/cancer-information/cancer-type/lung/ statistics/?region=on; cited 15 August 2015]

3. Berwick DM. A user's manual for the IOM's "Quality Chasm” report. Health Aff (Millwood) 2002;21:80-90.

4. BTS recommendations to respiratory physicians for organising the care of patients with lung cancer. The Lung Cancer Working Party of the British Thoracic Society Standards of Care Committee. Thorax 1998;53(suppl 1):S1-8.

5. Kmietowicz Z. Cancer guidelines from NICE aim to reduce variation in referral times. BMJ 2005;331:10. 
6. Allgar VL, Neal RD. Delays in the diagnosis of six cancers: analysis of data from the national survey of NHs patients: cancer. Br J Cancer 2005;92:1959-70.

7. United Kingdom, National Audit Office (NAO). NHS waiting times for elective care in England [online press release]. London, U.K.: NAO; 2014. [Available at: https://www.nao.org. uk/wp.../NHS-waiting-times; cited 20 August 2015]

8. Malin JL, Asch SM, Kerr EA, McGlynn EA. Evaluating the quality of cancer care: development of cancer quality indicators for a global quality assessment tool. Cancer 2000;88:701-7.

9. Olsson JK, Schultz EM, Gould MK. Timeliness of care in patients with lung cancer: a systematic review. Thorax 2009;64:749-56.

10. Lennes IT, Lynch TJ. Quality indicators in cancer care: development and implementation for improved health outcomes in non-small-cell lung cancer. Clin Lung Cancer 2009;10:341-6.

11. Goffredo P, Thomas SM, Adam MA, Sosa JA, Roman SA. Impact of timeliness of resection and thyroidectomy margin status on survival for patients with anaplastic thyroid cancer: an analysis of 335 cases. Ann Surg Oncol 2015;22:4166-7.

12. Forrest LF, Adams J, Rubin G, White M. The role of receipt and timeliness of treatment in socioeconomic inequalities in lung cancer survival: population-based, data-linkage study. Thorax 2015;70:138-45.

13. Zullig LL, CarpenterWR, Provenzale DT, et al. The association of race with timeliness of care and survival among Veterans Affairs health care system patients with late-stage non-small cell lung cancer. Cancer Manag Res 2013;5:157-63.

14. Radzikowska E, Roszkowski- li K, Głaz P. The impact of timeliness of care on survival in non-small cell lung cancer patients. Pneumonol Alergol Pol 2012;80:422-9.

15. Rusch VW, Asamura H, Watanabe H, Giroux DJ, Rami-Porta R, Goldstraw P on behalf of Members of IASLC Staging Committee. The IAsLC lung cancer staging project: a proposal for a new international lymph node map in the forthcoming seventh edition of the TNM classification for lung cancer. $J$ Thorac Oncol 2009;4:568-77.

16. Walters S, Maringe C, Coleman MP, et al. on behalf of the IсвP Module 1 Working Group. Lung cancer survival and stage at diagnosis in Australia, Canada, Denmark, Norway, Sweden and the UK: a population-based study, 2004-2007. Thorax 2013;68:551-64.

17. Cancer Quality Council of Ontario (CQCo). Wait Times for Diagnostic Assessment Program [Web page]. Toronto, ON: cQCo; n.d. [Available at: http://www.csqi.on.ca/by_patient_ journey/diagnosis/wait_times_for_diagnostic_assessment/; cited 27 August 2015]

18. Mathews M, Ryan D, Bulman D. Patient-expressed perceptions of wait-time causes and wait-related satisfaction. Curr Oncol 2015;22:105-12.

19. Deegan PC, Heath L, Brunskill J, Kinnear WJ, Morgan SA, Johnston ID. Reducing waiting times in lung cancer. J R Coll Physicians Lond 1998;32:339-43.

20. Newman EA, Guest AB, Helvie MA, et al. Changes in surgical management resulting from case review at a breast cancer multidisciplinary tumor board. Cancer 2006;107:2346-51.

21. Fleissig A, Jenkins V, Catt S, Fallowfield L. Multidisciplinary teams in cancer care: are they effective in the UK? Lancet Oncol 2006;7:935-43.
22. Evans SM, Earnest A, Bower W, Senthuren M, McLaughlin P, Stirling R. Timeliness of lung cancer care in Victoria: a retrospective cohort study. Med J Aust 2016;204:75.e1-9.

23. Nadpara PA, Madhavan SS, Tworek C. Disparities in lung cancer care and outcomes among elderly in a medically underserved state population-a cancer registry-linked database study. Popul Health Manag 2015;19:109-19.

24. Yorio JT, Xie Y, Yan J, Gerber DE. Lung cancer diagnostic and treatment intervals in the United States: a health care disparity? J Thorac Oncol 2009;4:1322-30.

25. LiX, Scarfe A, King K, Fenton D, Butts C, Winget M. Timeliness of cancer care from diagnosis to treatment: a comparison between patients with breast, colon, rectal or lung cancer. Int J Qual Health Care 2013;25:197-204.

26. Forrest LF, Adams J, White M, Rubin G. Factors associated with timeliness of post-primary care referral, diagnosis and treatment for lung cancer: population-based, data-linkage study. Br J Cancer 2014;111:1843-51.

27. Bilimoria KY, Ko CY, Tomlinson JS, et al. Wait times for cancer surgery in the United States: trends and predictors of delays. Ann Surg 2011;253:779-85.

28. Bardell T, Belliveau P, Kong W, Mackillop WJ. Waiting times for cancer surgery in Ontario: 1984-2000. Clin Oncol (R Coll Radiol) 2006;18:401-9.

29. Liberman M, Liberman D, Sampalis JS, Mulder DS. Delays to surgery in non-small-cell lung cancer. Can JSurg 2006;49:31-6.

30. Lee J, Marchbank A, Goldstraw P. Implementation of the British Thoracic Society recommendations for organising the care of patients with lung cancer: the surgeon's perspective. Ann R Coll Surg Engl 2002;84:304-8.

31. Nadpara PA, Madhavan SS, Tworek C, Sambamoorthi U, Hendryx M, Almubarak M. Guideline-concordant lung cancer care and associated health outcomes among elderly patients in the United States. J Geriatr Oncol 2015;6:101-10.

32. Johnston GM, MacGarvie VL, Elliott D, Dewar RA, MacIntyre MM, Nolan MC. Radiotherapy wait times for patients with a diagnosis of invasive cancer, 1992-2000. Clin Invest Med 2004;27:142-56.

33. Salomaa ER, Sällinen S, Hiekkanen H, Liippo K. Delays in the diagnosis and treatment of lung cancer. Chest 2005;128:2282-8.

34. Coleman MP, Foreman D, Bryant H, et al. on behalf of the ICBP Module 1 Working Group. Cancer survival in Australia, Canada, Denmark, Norway, Sweden, and the U.K., 1995-2007 (the International Cancer Benchmarking Partnership): an analysis of population-based cancer registry data. Lancet 2011;377:127-38.

35. Chen Z, King W, Pearcey R, Kerba M, Mackillop WJ. The relationship between waiting time for radiotherapy and clinical outcomes: a systematic review of the literature. Radiother Oncol 2008;87:3-16.

36. Yilmaz A, Damadoglu E, Salturk C, Okur E, Tuncer LY, Halezeroglu S. Delays in the diagnosis and treatment of primary lung cancer: are longer delays associated with advanced pathological stage? Ups J Med Sci 2008;113:287-96.

37. Mohammed N, Kestin LL, Grills IS, et al. Rapid disease progression with delay in treatment of non-small-cell lung cancer. Int J Radiat Oncol Biol Phys 2011;79:466-72.

38. Gonzalez-Barcala FJ, Falagan JA, Garcia-Prim JM, et al. Timeliness of care and prognosis in patients with lung cancer. Ir J Med Sci 2014;183:383-90. 